\title{
Space maintainers application, indication and complications
}

\author{
Mohammed Albati ${ }^{1}{ }^{*}$, Riham Showlag $^{2}$, Alaa Akili ${ }^{1}$, Halah Hanafiyyah ${ }^{1}$, Hanadi AlNashri ${ }^{1}$, \\ Waad Aladwani ${ }^{1}$, Ghaida Alfarsi ${ }^{1}$, Mashael Alharbi ${ }^{1}$, Abdulrahman Almutairi ${ }^{3}$
}

College of Dentistry, ${ }^{1}$ Alfarabi Colleges, Jeddah, ${ }^{3}$ Qassim Private Colleges, Qassim, Saudi Arabia

${ }^{2}$ Department of Dentistry, North Jeddah Speciality Dental Center, Jeddah, Saudi Arabia

Received: 27 September 2018

Revised: 11 October 2018

Accepted: 13 October 2018

\section{*Correspondence:}

Dr. Mohammed Albati,

E-mail: mab-2009@hotmail.com

Copyright: (C) the author(s), publisher and licensee Medip Academy. This is an open-access article distributed under the terms of the Creative Commons Attribution Non-Commercial License, which permits unrestricted non-commercial use, distribution, and reproduction in any medium, provided the original work is properly cited.

\section{ABSTRACT}

Dental space maintenance is essential in cases of premature loss of primary dentition to prevent malposition, supraeruption, impaction, or crowding of the developing permanent teeth. Many types of space maintainers are available and each type is specifically designated for particular indications. Space maintainers have many classifications according to their design, their fixation pattern, their position, and their site. They can be fixed, semi-fixed, or removable, with or without loops, wires, and/or bands, unilateral or bilateral, and are placed on mandibular or maxillary arches. The most commonly used space maintainers are loops and bands, fixed lingual arches, Nance appliances, and transpalatal arches. Though space maintainers are generally safe, several complications are sometimes inevitable. This article will review the different types of space maintainers and their application and will discuss their indications and potential complications.

Keywords: Application, Bands, Complications, Dental appliances, Fixed lingual arch, Indications, Loops, Nance appliance, Space maintainers, Transpalatal arch

\section{INTRODUCTION}

Under normal physiological conditions, the child loses his primary teeth and they are replaced by well-fitting normal teeth. However, the dentation may be disrupted due to certain pathological conditions such as teeth caries, trauma, abnormal resorption, or systemic diseases leading to premature loss of dentition. ${ }^{1}$ This results in migration of the existing teeth and loss of arch space which subsequently lead to impairment of the normal configuration of the newly developing permanent teeth. ${ }^{2}$ The most common impairment in permanent dentition configuration include crowing, supra-eruption of the opposing dentition, and impaction. ${ }^{3}$

To avoid these dental conditions, a space maintainer is indicated to keep an adequate space for the newly developing teeth to erupt and exfoliate naturally in a well-aligned position. ${ }^{4}$ Under normal physiological condition, the primitive teeth are considered the normal space maintainers for the permanent teeth to exfoliate. ${ }^{5}$ In conditions where the primitive teeth are prematurely lost, an artificial space maintainer is necessary for normal exfoliation of normal teeth.

In this article, types and application of space maintainers will be reviewed, and the indications and complications will be discussed.

\section{TYPES AND APPLICATIONS OF SPACE MAINTAINERS}

Space maintainers are applicable dental devices specifically designed to maintain a space or to create an additional space that was lost due to premature loss of primitive teeth. ${ }^{6}$ The space maintainers do not play a role 
in development of new teeth. The main function of the space maintainers appliances is to guide the eruption of the new dentition in an appropriate space to prevent impaction, crowding, or supra-eruption. ${ }^{7}$

Many types and designs were developed and are available for space maintenance after primary dentition. Each type is specifically designated to serve a purpose and to suit certain indications. An ideal space maintainer should maintain the entire space on mesiodistally that was created after loss of the primitive teeth. ${ }^{4}$ It should be simple in construction, of adequate strength to withstand the shearing and functional forces, and to allow restoration of as much function as possible. ${ }^{1}$ It should also allow adequate oral hygiene, permit normal growth and adjustment of the developing permanent teeth, and to prevent opposing teeth supra-eruption and undue stress on adjoining teeth. ${ }^{2}$ The available space maintainers are of various types. They are broadly classified according to their fixation pattern (i.e. fixed, semi-fixed, or removable), their construction (e.g. with or without loops, wires, and/or bands), their laterality (i.e. unilateral or bilateral), and their site (i.e. on mandibular or maxillary arches). ${ }^{2,4,8}$ A wide variation exists by combining variable forms of these types. Basically, the main advantages of the fixed space maintainers are they do not interfere with jaw growth or new teeth development and eruption, they do not require teeth preparation, and they do not interfere with mastication particularly when pontics are placed. ${ }^{9}$ Furthermore, they allow an adequate space for the newly growing permanent teeth to erupt naturally in the oral cavity. Fixed space maintainers are the appliances of choice in un-cooperative patients. However, they require skillful experts for proper handling of the instruments and appropriate placement of the appliances. ${ }^{10}$ The use of pontics may also result in interference with proper vertical eruption of the maintenance teeth. Moreover, the teeth are exposed to decalcification under the fixed maintainers bands. ${ }^{11}$ Bands may also impair mastication, prevent normal movement of the primary cuspid distally during lateral incisor permanent eruption, and result in supra-eruption of opposing teeth. Examples of the space maintainers include lingual arch appliances for bilateral fixed mandibular space maintenance, mandibular removable space maintainers, mandibular unilateral crown and loop space maintainer, trans-palatal arches, Nance appliances, and bands and loops. ${ }^{12-14}$

The application of space maintainers varies according to its construction and its meant function. Basically, most of the space maintainers are applied in four steps namely band finding, taking the impression, fabrication of space maintainer, and finally cementation. ${ }^{4,15}$ Removable space maintainers ae applied in three steps excluding the first of the aforementioned steps. The process of band fitting is carried out through a trial and error procedure via tying multiple of the available bands in the band sit to choose the most suitable band that fits the size of the tooth to be banded. ${ }^{16}$ In cases with tight teeth that cannot be easily separated, elastics may be required prior to placement of bands. The bands are then placed on the tooth and finger pressure is applied. Further pressure can be carried out using the band seater handle or a tongue depressor and asking the patient to step on them. Using a band seater handle or a tongue depressor carries the advantage of preventing the undue crushing of the band during the placement procedure. ${ }^{7}$ Band pliers and/or band pushers may be necessary at final steps of band fixation. Having the bands successfully placed, taking impressions comes into action. The main substances utilized for impression taking are compound and alginate. ${ }^{17,18}$ Alginate is mainly utilized when removable appliances are placed. ${ }^{17}$ Compound, on the other hand, is used with fixed appliances because of its high stability and accuracy. ${ }^{18}$ Taking impression may be carried out with or without impression trays. Impressions are usually used for bilateral rather than unilateral fixed space maintainers application. The impression-taking material is first softened in hot water, then placed in an appropriately sized tray and further warmed. ${ }^{3}$ After being left for a while to cool, the impression material is placed in the patient's mouth and left there for few seconds to minutes to dry. A continuous air flow may aid in fastening the process of hardening, and then the well-casted material is removed from the patient's mouth. ${ }^{19}$ The third step of space maintainer application is the fabrication. Fabrication is the process of imaginary creation of the design and construction of the required space maintainer via using the already prepared casts or molds. Various constructions can be accurately built, and the cementation process takes place next. The space maintainers must first be ensured to fit inside the oral cavity exactly as it does on the cast before cementation. ${ }^{20,21}$ Many materials can be used for cementation such as zinc phosphate and glass ionomer. $^{22-24}$ Zinc phosphate cement is generally preferred for its tolerability by the vast majority of patients and its easy storage. ${ }^{22}$ However, glass ionomer became more popular in the past few decades due to its added advantages such as less solubility, less liability to decay, and its fluoride-releasing property. ${ }^{23,24}$

\section{INDICATIONS OF SPACE MAINTAINERS}

As aforementioned, the use of space maintainers is indicated in case of premature loss of primary dentition when concern exists as regards the proper development and alignment of the newly growing dentition. ${ }^{25}$ However, not all patients who lose their primary dentition early necessarily require dental appliances. For instance, patients who have widely spaced primary dentition would not benefit from space maintenance. ${ }^{3}$ Similarly, those whose succeeding teeth are expected to erupt within the next six month do not need dental space maintainers. Also, those who have cuspal interference or locked opposing first molars in a stable relationship do not require space maintenance. Finally, patients who are expected to have future orthodontic procedures for any other indications are not recommended to place space maintaining appliances. ${ }^{4,25}$ 
Each type of space maintainers is indicated in particular situations. For instance, bands and loops are preferred in cases of premature loss of a primitive second molar specifically when the permanent first molar has erupted. They are also used in cases of premature loss of maxillary primary molars during the transitional dentition or any primary molars in primitive dentition if the permanent succeeding molars failed to erupt two years after or if their root was shorter than its expected full length during this two-year period. Also, the bands and loops can be used in cases of bilateral loss of primitive molars only if the permanent incisors have not yet developed. ${ }^{11,26}$ The main contraindications for loops and bands appliances are active dental caries, overcrowding, marked space loss, space maintenance for anterior teeth, and space maintenance for second molars in transitional dentition. ${ }^{20}$

Fixed lingual arches, on the other side, are best suited in space maintenance in the lower dental arch. Fixed lingual arch is a bilateral fixed space maintaining appliance that consists of an arch with two bands cemented to the first permanent molars bilaterally and a wire butting against the lower four permanent incisors. ${ }^{27}$ The main advantages of fixed lingual arches are their relative stability, ease of cleaning, patient comfort, and permission of permanent teeth eruption without interference. ${ }^{28}$ However, they do not prevent eruption of opposing teeth and they are not suitable for hypocalified hypoplastic teeth or teeth with caries. $^{28}$ They are chiefly indicated for prevention of mandibular arch changes during the transitional dentition of lower incisors, prevention of anterior crowding and change of position of mandibular incisors, and as a base for cosmetic restoration of anterior teeth (Hollywood appliance). ${ }^{10,16}$ Fixed lingual arches do not suit cases that require frequent adjustment of appliances, patients with excessive anterior crowding, or those with anterior or posterior crossbite. ${ }^{27}$

Nance appliances are closely similar space maintainers that do not contact the anterior teeth. They are composed of a band and a palatal wire. The band is placed around the permanent molars, whilst the palatal wire approximates the anterior palate providing a resistance against anterior movement of the posterior teeth. The Nance appliances have the same indications of the fixed lingual arches. Because of their soft tissue contact, their main disadvantage is discomfort and soft tissue irritation. $^{14}$

The fourth type of dental appliance is the transpalatal arch. The transpalatal arch is a special type of dental maintainers that runs horizontally across the palate connecting bilateral molars. The main advantage of this appliance is that it does not contact the soft tissue and is subsequently associated with minimal irritation or discomfort. The main function of transpalatal arch is preventing the mesiolingual rotation of maxillary molars during development. Therefore, it is best indicated when several primary molars are lost one side on the maxillary arch whereas the other side is intact. In cases of bilateral loss of primary molars, trasnpalatal arch cannot be used and a Nance appliance or fixed lingual arch can substitute. $^{29,30}$

\section{COMPLICATIONS OF SPACE MAINTAINERS}

Though considered generally safe, space maintainers carry the risk of several potential complications. The main complications include increased risk of infection, dental caries, plaque accumulation, local pain and discomfort, interference with the normal development and alignment of the erupting succeeding teeth, undesirable teeth position and movement, soft tissue irritation and impingement, and complications related to the appliances e.g. breakage, loss, or dislodgement.

Infection remains one of the most serious and most studied complications. Researchers reported that both removable and fixed dental space maintainers are associated with a significantly high risk of oral cavity microorganism growth and increased periodontal index scores. ${ }^{31}$ Candida was found to be commonly encountered in patients with removable dental appliances whereas salivary Enterococcus faecalis was isolated from fixed appliances. ${ }^{31}$

Appliances with direct contact to the mucosa and soft tissue, such as loops, bands, and lingual arches, are potentially complicated with soft tissue impingement, ulceration, bleeding, and pain. Gingival hyperplasia and mucosal overgrowth are also commonly encountered. Complications related to the dental appliances such as dislodgment or displacement are commonly found with bands and loops. ${ }^{32}$

Most of the complications of dental space maintainers are preventable. Patient education and close regular monitoring are the key for successful prevention and early detection and management of any potential complications. Education about oral hygiene and appropriate cleansing of the dental appliances is essential. Education about avoiding chewing on hard foods and eating sticky gums or candies is important to avoid loosening and failure of the dental appliances. ${ }^{7,20}$ Early identification of signs of infection, caries, or disintegration is fundamental for prevention of worsening of these complications. ${ }^{31}$

\section{CONCLUSION}

Dental space maintenance is essential in cases of premature loss of primary dentition to prevent malposition, supra-eruption, or crowding of the developing permanent teeth. Many types of space maintainers are available and each type is specifically designated for particular indications. Space maintainers are fixed, semi-fixed, or removable, with or without loops, wires, and/or bands, unilateral or bilateral, and are placed on mandibular or maxillary arches. The most commonly used space maintainers are loops and bands, 
fixed lingual arches, Nance appliances, and trans palatal arches. Space maintainers are generally safe. However, several complications are sometimes inevitable such as infection, dental caries, plaque accumulation, local pain and discomfort, interference with the normal development and alignment of the erupting succeeding teeth, undesirable teeth position and movement, soft tissue irritation and impingement, and appliances breakage, loss, or dislodgement.

Funding: No funding sources

Conflict of interest: None declared

Ethical approval: Not required

\section{REFERENCES}

1. Barberia E, Lucavechi T, Cardenas D, Maroto M. Free-end space maintainers: design, utilization and advantages. J Clin Pediatr Dent. 2006;31(1):5-8.

2. Tunison W, Flores-Mir C, ElBadrawy H, Nassar U, El-Bialy T. Dental arch space changes following premature loss of primary first molars: a systematic review. Pediatr Dent. 2008;30(4):297-302.

3. Setia V, Pandit IK, Srivastava N, Gugnani N, Sekhon HK. Space maintainers in dentistry: past to present. J Clin Diagnos Res. 2013;7(10):2402-5.

4. Laing E, Ashley P, Naini FB, Gill DS. Space maintenance. Int J Paediatr Dent. 2009;19(3):15562.

5. Rao AK, Sarkar S. Changes in the arch length following premature loss of deciduous molars. J Indian Soc Pedod Prev Dent. 1999;17(1):29-32.

6. Lin Y-TJ, Lin Y-T. Long-term space changes after premature loss of a primary maxillary first molar. $\mathbf{J}$ Dent Sci. 2017;12(1):44-8.

7. Woods WD. Space Maintainers. J Am Dent Assoc. 2010;141(5):501-2.

8. Leifert MF, Leifert MM, Efstratiadis SS, Cangialosi TJ. Comparison of space analysis evaluations with digital models and plaster dental casts. Am J Orthod Dentofac Orthop. 2009;136(1):16.

9. Patil PG. Implants Or Pontics. J Am Dent Assoc. 2010;141(1):14-5.

10. Roberts-Harry D, Sandy J. Orthodontics. Part 5: Appliance choices. Br Dent J. 2006;196:9.

11. Fathian M, Kennedy DB, Nouri MR. Laboratorymade space maintainers: a 7-year retrospective study from private pediatric dental practice. Pediatric Dentistry. 2007;29(6):500-6.

12. Kupietzky A, Tal E. The transpalatal arch: an alternative to the Nance appliance for space maintenance. Pediatric Dentistry. 2007;29(3):235-8.

13. Al-Awadhi EA, Garvey TM, Alhag M, Claffey NM, O'Connell B. Efficacy of the Nance appliance as an anchorage-reinforcement method. Am J Orthod Dentofac Orthop. 2015;147(3):330-8.

14. Singh P, Cox S. Nance palatal arch: a cautionary tale. J Orthod. 2009;36(4):272-6.

15. Tayab T, Vizhi K, Srinivasan I. Space maintainer using fiber-reinforced composite and natural tooth-- a non-invasive technique. Dent Traumatol. 2011;27(2):159-62.

16. Ahmad AJ, Parekh S, Ashley PF. Methods of space maintenance for premature loss of a primary molar: a review. European archives of paediatric dentistry: official J Euro Acad Paediatric Dent. 2018.

17. Xu HH, Weir MD, Simon CG. Injectable and strong nano-apatite scaffolds for cell/growth factor delivery and bone regeneration. Dent Mater. 2008;24(9):1212-22.

18. Chiang YC, Chang HH, Wong CC, Wang YP, Wang YL, Huang WH, et al. Nanocrystalline calcium sulfate/hydroxyapatite biphasic compound as a TGF-beta1/VEGF reservoir for vital pulp therapy. Dent Mater. 2016;32(10):1197-208.

19. Appliance Construction: Impression Taking. https://depts.washington.edu/peddent/AtlasDemo/sp ace091.html. Accessed 18 September 2018.

20. Nayak UA, Loius J, Sajeev R, Peter J. Band and loop space maintainer--made easy. J Indian Soc Pedod Prev Dent. 2004;22(3):134-6.

21. Brill WA. The distal shoe space maintainer chairside fabrication and clinical performance. Pediatr Dentist. 2002;24(6):561-5.

22. Behr M, Rosentritt M, Wimmer J, Lang R, Kolbeck C, Burgers R, et al. Self-adhesive resin cement versus zinc phosphate luting material: a prospective clinical trial begun 2003. Dent Mater. 2009;25(5):601-4.

23. Khoroushi M, Keshani F. A review of glassionomers: From conventional glass-ionomer to bioactive glass-ionomer. ENT Res J (Isfahan). 2013;10(4):411-20.

24. Davidson CL. Advances in glass-ionomer cements. J Appl Oral Sci. 2006;14:3-9.

25. Morais N, Faustino F, Morais T, Kassis EN, de Castro FPL, Scriboni AB, et al. Dental space maintainers: a brief review. Int $J$ Adv Res. 2016;4(10):2086-92.

26. Cornelius CP, Ehrenfeld M. The Use of MMF Screws: Surgical Technique, Indications, Contraindications, and Common Problems in Review of the Literature. Craniomaxillofac Trauma Reconstr. 2010;3(2):55-80.

27. Housley JA, Nanda RS, Currier GF, McCune DE. Stability of transverse expansion in the mandibular arch. Am J Orthod Dentofac Orthop. 2003;124(3):288-93.

28. Eliasson A, Palmqvist S, Svenson B, Sondell K. Five-year results with fixed complete-arch mandibular prostheses supported by 4 implants. Int $\mathbf{J}$ Oral Maxillofac Implants. 2000;15(4):505-10.

29. Zablocki HL, McNamara JA, Jr., Franchi L, Baccetti T. Effect of the transpalatal arch during extraction treatment. Am J Orthod Dentofac Orthop. 2008;133(6):852-60.

30. Kumar ND, Krishna BRG, Shamnur N, Mithun K. Modified Transpalatal Arch for Molar Intrusion. J Int oral Heal JIOH. 2014;6(6):88-9. 
31. Arikan V, Kizilci E, Ozalp N, Ozcelik B. Effects of Fixed and Removable Space Maintainers on Plaque Accumulation, Periodontal Health, Candidal and Enterococcus Faecalis Carriage. Med Princ Pract. 2015;24(4):311-7.

32. Chandra SH, Krishnamoorthy SH, Johnson JS, Prabhu S. ILL effects of Conventional band and loop space maintainers \#\#time to revolutionise. Int Dent Med J Adv Res. 2018;4:1-4.

Cite this article as: Albati M, Showlag R, Akili A, Hanafiyyah H, AlNashri H, Aladwani W, et al. Space maintainers application, indication and complications. Int J Community Med Public Health 2018;5:4970-4. 